\title{
Palliatieve dementiezorg verlenen tijdens COVID-19
}

auteurs

SASCHA BOLT

JENNY VAN DER

STEEN

IRMA

MUJEZINOVÍC

DAISY JANSSEN

JOS SCHOLS

SANDRA

ZWAKHALEN

CHANDNI

KHEMAI

ELS KNAPEN

LARA DIJKSTRA

INGE JOCHEM

JOLANDA

TIMMERMANS

JUDITH MEIJERS

\section{()}

CORRESPONDENTIE

JUDITH MEIJERS

J.MEIJERS@

MAASTRICHTUNIVERSITY.NL
De COVID-19-pandemie heeft voor verpleegkundigen tot de uitdaging geleid ook in deze nieuwe situatie goede palliatieve zorg te verlenen aan mensen met dementie. Op basis van 25 artikelen formuleren de auteurs praktische adviezen.

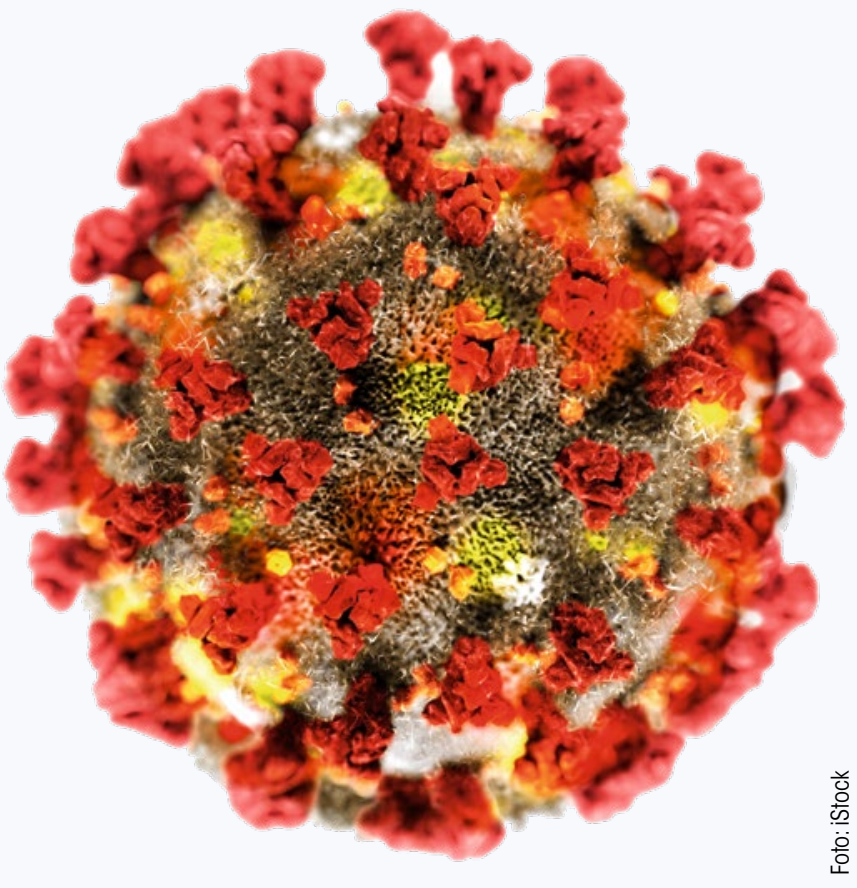

TREFWOORDEN

$\rightarrow$ Dementie

$\rightarrow$ Palliatieve zorg

De Wereldgezondheidsorganisatie (WHO) heeft op 11 maart 2020

COVID-19 als pandemie bestempeld. ${ }^{1}$

Gegevens uit Italië en China wijzen erop dat onder mensen ouder dan 80 jaar sterftecijfers 11 tot 20 keer hoger liggen dan in de leeftijdscategorie 50-59 jaar. ${ }^{2}$ Mensen met dementie vormen een erg kwetsbare groep, die risico loopt op negatieve gevolgen van COVID-19, inclusief overlijden. ${ }^{3-4} \mathrm{Zij}$ hebben mogelijk ook een grotere kans op infectie omdat ze beschermende maatregelen, zoals zelfisolatie en handdesinfectie, niet kunnen onthouden of begrijpen. ${ }^{4-5}$ Onderwerpen rondom sterven en de dood zijn door de COVID-19-crisis snel onder de aandacht gekomen. Het faciliteren van vroegtijdige levenseindegesprekken en advance care planning (ACP) zijn hoekstenen van palliatieve zorg. Dat geldt ook voor het verlichten van pijn en andere hinderlijke symptomen, het vergroten van comfort en het ondersteunen van naasten voor en na het verlies. ${ }^{6}$ Voor verpleegkundig personeel in de langdurige zorg leidt de COVID-19-pandemie tot uitdagingen bij het verlenen van kwalitatief goede palliatieve zorg aan mensen met dementie (met of zonder COVID-19). 


\title{
FIGUUR 1 PRAKTISCHE HANDVATTEN VOOR PALLIATIEVE ZORG BIJ MENSEN MET DEMENTIE IN TIJDEN VAN COVID-19 (ALLE HANDVATTEN VINDT U OP TVZDIRECT.NL)
}

\section{Praktische handvatten voor palliatieve zorg bij mensen met dementie in tijden van COVID-19}

\author{
Advance Care Planning (ACP)
}

Probeer het onderwerp COVID-19 voorzichtig in te leiden. Geef eerlijke informatie over COVID-19 en de mogelijk slechte prognose. Geef mensen vervolgens de ruimte om hun wensen en zorgvoorkeuren uit te spreken.

Door ACP-gesprekken te voeren met mensen met dementie of hun naasten in het kader van COVID-19 kunnen ongewenste ziekenhuisopnames en behandelingen worden voorkomen. Houd er rekening mee dat, wanneer ACP gesprekken niet eerder plaatsvonden, de eerste ACP-gesprekken ten tijde van COVID-19 gekleurd kunnen zijn door angst of emoties.

Extra aandachtspunten bij mensen met dementie die COVID-19 hebben:

Bespreek zo snel mogelijk de zorgdoelen binnen het interprofessionele zorgteam. Pas de zorgdoelen steeds aan als de situatie verandert.

Besteed in ACP-gesprekken aandacht aan emoties (ook van naasten) en geef uitleg over anticiperende rouw. Bereid mensen voor op een mogelijk levenseinde als gevolg van COVID-19

Ga herhaaldelijk ACP-gesprekken aan, om proactief mogelijke scenario's te bespreken. Zorg voor duidelijke documentatie van wensen, zodat deze in een acute situatie beschikbaar zijn.

Stel wanneer de situatie verandert de zorgplannen en zorgdoelen bij. Bespreek dit met de betrokkenen (persoon met dementie, naasten en het zorgteam) en leg de nieuwe plannen vast.
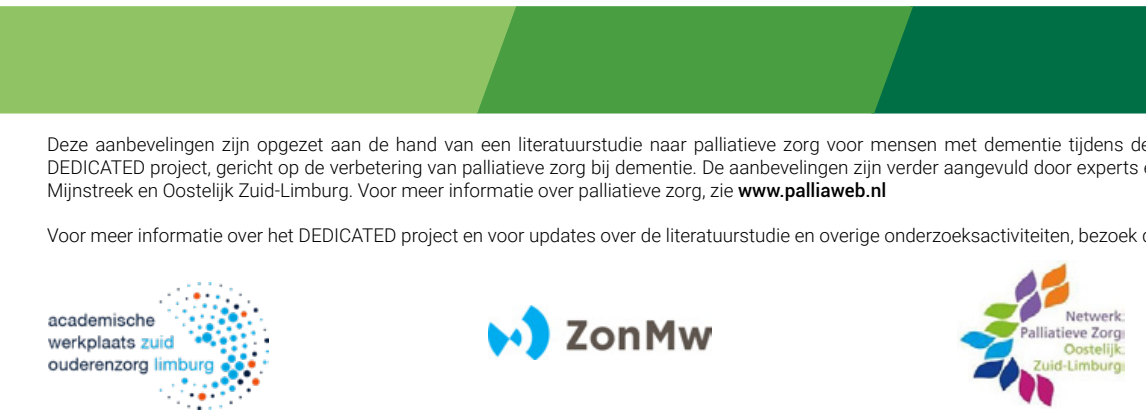

ZonMw

Dit artikel beschrijft een rapid scoping review en hieruit volgende praktijkaanbevelingen voor verpleegkundig personeel met betrekking tot palliatieve dementiezorg in tijden van COVID-19.

\section{METHODEN}

Deze rapid scoping review is onderdeel van het onderzoeksproject DEDICATED: Desired Dementia Care Towards End of Life. DEDICATED richt zich op het verbeteren van palliatieve zorg voor mensen met dementie en hun naasten. Tussen 14 april en 18 mei 2020 is wekelijks literatuur gezocht. De zoekstrategie omvatte vier stappen, volgens de handleiding van het Joanna Briggs Institute. Het gaat om:

1. Het doorzoeken van databases

PubMed, CINAHL en PsycINFO voor relevante zoekwoorden.
2. Het doorzoeken van de databases met uitgewerkte zoekstring.

3. Het handmatig doorzoeken van referentielijsten.

4. Het doorzoeken van grijze literatuur via Google.

$\mathrm{Na}$ het (onafhankelijk) screenen van titels en abstracts werden door twee van de auteurs volledige teksten verkregen en beoordeeld op geschiktheid tot er volledige overeenstemming was.

Deze auteurs bespraken ook gegevens en bevindingen en formuleerden praktische aanbevelingen. De aanbevelingen werden gecategoriseerd volgens de vier domeinen van palliatieve zorg: fysieke, psychologische, sociale aspecten en spirituele aspecten van zorg. Op basis van inductieve bevindingen uit de review hebben we aanbevelingen toegevoegd voor ACP en zorg voor stervenden en nabestaanden. Deze lijst met aanbevelingen werd besproken met alle auteurs om tot een definitieve lijst te komen.

\section{RESULTATEN}

We bekeken 163 unieke titels. Van 55 titels hebben we volledige teksten verkregen en gescreend. Uiteindelijk werden 25 artikelen geïncludeerd. De artikelen waren afkomstig uit het Verenigd Koninkrijk en Ierland $(n=8)$, Europa $(n=6)$, de Verenigde Staten $(n=$ $3)$, Australië $(n=3)$, Canada $(n=2)$ en Azië $(n=2)$. Het laatste artikel was internationaal (zie www.academischewerkplaatsouderenzorg.nl/sites/intranet. mumc.maastrichtuniversity.nl/files/ awo/public_article/appendix_1.pdf). Op basis van de geïncludeerde artikelen is een lijst met aanbevelingen opgezet 
FIGUUR 2 FLOWCHART VAN HET ZOEK- EN SELECTIEPROCES

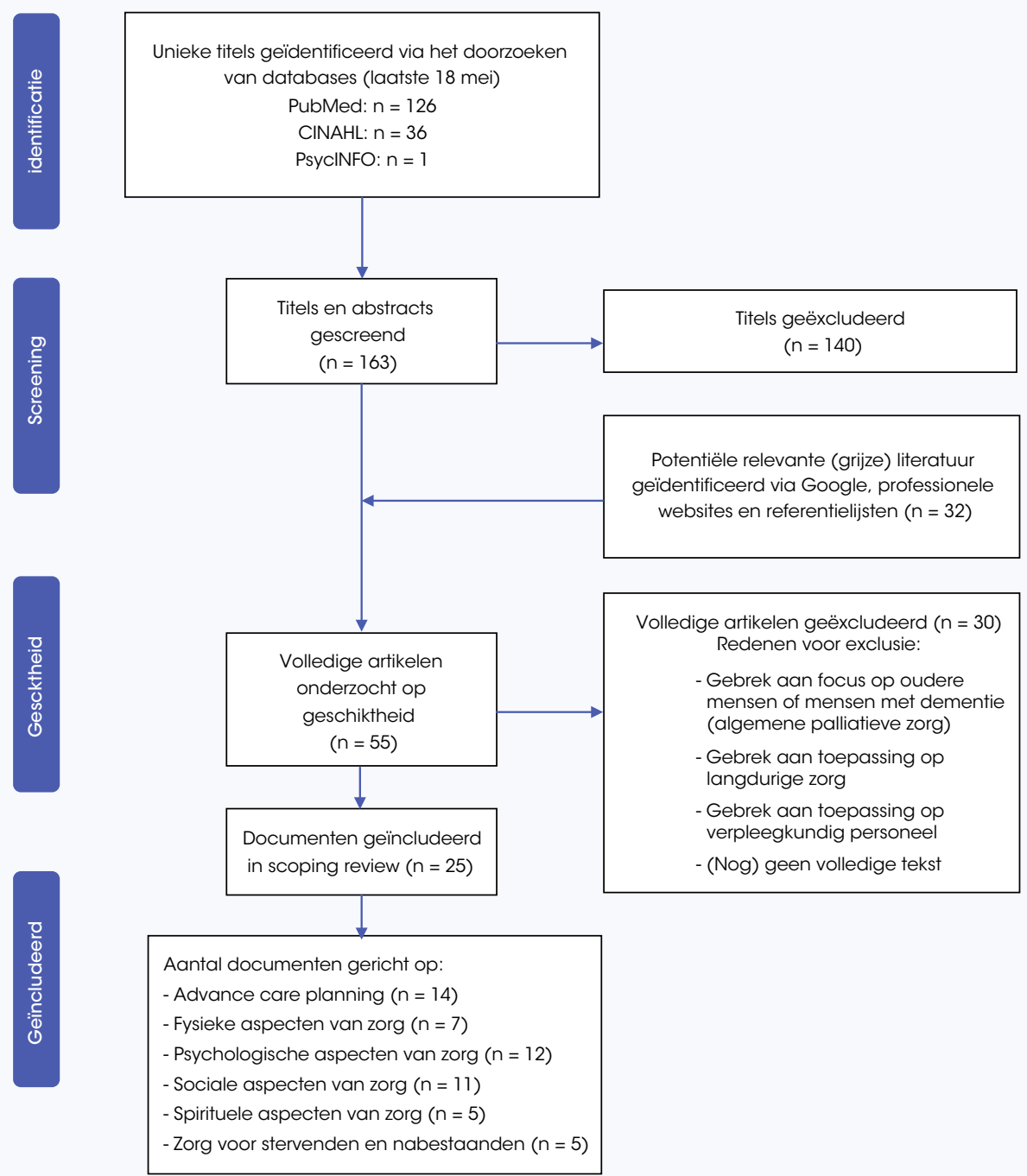

voor verpleegkundig personeel met betrekking tot palliatieve zorg voor mensen met dementie tijdens de COVID-19-pandemie (zie figuur 1). De domeinen die door het grootste aantal artikelen werden onderbouwd, zijn 'advance care planning' en 'psychologische aspecten van zorg' (zie figuur 2). De domeinen die door het kleinste aantal artikelen werden onderbouwd, zijn 'zorg voor stervenden en nabestaanden' en 'spirituele aspecten van zorg'.

\section{DISCUSSIE}

Dit artikel beschrijft een rapid scoping review en praktijkaanbevelingen voor verpleegkundig personeel met betrek- king tot palliatieve dementiezorg in tijden van COVID-19. Aanvankelijk vonden we vooral artikelen over ACP en fysieke of medische zorg voor COVID-19-patiënten. Artikelen over psychologische, sociale en spirituele zorg en over verpleegkundige zorg waren schaars, maar mettertijd verschenen er meer artikelen die deze domeinen en de impact van de COVID-19-pandemie op (de zorg voor) mensen met dementie beschreven. Er waren weinig specifieke artikelen over palliatieve zorg voor mensen met dementie in verband met COVID-19. Dit illustreert dat, ondanks de toegenomen aandacht in de afgelopen twee decennia voor palliatieve zorg bij dementie, het geen topprioriteit is wanneer zich een crisis voordoet. ${ }^{8-9}$ Hierin zijn nog altijd barrières. Te denken valt aan het gebrek aan bewustzijn over dementie als een terminale aandoening en een gebrek aan mogelijkheden voor (verpleegkundig) zorgpersoneel om de vaardigheden en kennis te vergroten. ${ }^{10}$ De pandemie openbaart deze hiaten en benadrukt de behoefte aan een geïntegreerde palliatieve benadering in de wereldwijde gezondheidszorg voor mensen met dementie. ${ }^{11}$

ACP en gedeelde besluitvorming zijn kernprocessen bij het vaststellen van zorgdoelen voor mensen met dementie. ${ }^{6}$ Ze kunnen ongewenste levensverlengende behandelingen helpen voorkomen. Dit is van cruciaal belang tijdens deze pandemie. Toch wordt de autonomie om te kiezen voor levensverlengende behandelingen of de plaats van overlijden mogelijk op de proef gesteld in deze periode - als gevolg van overheidsmaatregelen en tekorten in de gezondheidszorg. ${ }^{4}$ Als mensen met dementie niet in aanmerking komen voor levensverlengende behandelingen of een ziekenhuisopname, is het nog altijd een mensenrecht dat palliatieve zorg en de verlichting van lijden hun niet worden ontzegd. ${ }^{3,12-13}$ Stigma verhoogt het risico op ontzegging van gezondheidszorg en sociale diensten. ${ }^{4}$ Verpleegkundigen zijn onmisbaar als belangenbehartigers voor mensen met dementie en om hen te beschermen tegen de negatieve gevolgen van deze stigmatisering.

Voor goede palliatieve zorg in tijden van een pandemie, is het essentieel om zorgplannen binnen het interprofessionele zorgteam te herzien en de zorgdoelen bij te stellen via ACP-gesprekken met mensen met dementie en hun naasten. ${ }^{14-16}$ In het kader van COVID-19 kan besluitvorming bijzonder uitdagend zijn vanwege beperkte middelen. Dit kan leiden tot morele nood. Die ontstaat wanneer beperkingen ons ervan weerhouden te doen wat wij denken dat moreel juist is, hetgeen kan resulteren in complexe rouw en burn-out bij naasten en verpleegkundig personeel. ${ }^{17} \mathrm{Het}$ is belangrijk dat verpleegkundig personeel over deze negatieve emoties open 


\section{'Verpleegkundi- gen zijn onmis- bare belangen- behartigers voor mensen met dementie'}

communiceert met (interprofessionele) collega's en naasten. De huidige pandemie benadrukt dan ook de noodzaak van verpleegkundig leiderschap. Verpleegkundig personeel en naasten stellen het welzijn van de persoon met dementie vaak boven hun eigen gevoelens. Desalniettemin moeten we zelfzorg stimuleren in tijden van de COVID-19-pandemie. We dienen ook het zelfbewustzijn van naasten en verpleegkundig personeel over (negatieve) emoties en gedachten tijdens de zorgverlening te vergroten.

In de aanbevelingen van deze review is zorg voor stervenden en nabestaanden opgenomen als apart domein. Door de plotselinge en snelle achteruitgang die COVID-19 kan veroorzaken, kunnen naasten en verpleegkundig personeel zich onvoorbereid voelen op het verlies van een persoon. ${ }^{17-18}$ In combinatie met het mogelijke onvermogen om lichamelijk contact te hebben met de stervende, of de aanblik van de ander bij diens levenseinde, kan dit het risico op gecompliceerde rouw vergroten. ${ }^{18} \mathrm{Niet}$ in staat zijn goed afscheid te nemen, houdt verband met depressie na het verlies en met gecompliceerde rouw. ${ }^{16,19}$ Bovendien dwingen maatregelen in tijden van COVID-19 ertoe begrafenissen een andere vorm te geven, soms zonder fysieke aanwezigheid en aanraking van familieleden en vrienden. ${ }^{18} \mathrm{Al}$ deze factoren dragen bij aan het risico op trauma, posttraumatische stressstoornissen (PTSS), gevoelens van verlating of eenzaamheid. De complexiteit van rouw en verlies in tijden van COVID-19 benadrukt de rol van verpleegkundig personeel op een aantal vlakken. Het gaat om het herkennen en aankaarten van anticiperende rouw, het voorbereiden van naasten op het verlies en het helpen van naasten om hun verlies te verwerken als onderdeel van palliatieve zorg. ${ }^{17,20}$ Zoals Dame Cicely Saunders ooit zei: 'Hoe mensen sterven, blijft in het geheugen van degenen die voortleven.'

\section{REFERENTIES \\ 1. World Health Organization. Rolling updates on coronavirus disease (COVID-19). 2020. \\ 2. Onder G, Rezza G \& Brusaferro S. Case-Fatality Rate and Characteristics of Patients Dying in Relation to COVID-19 in Italy. JAMA. 2020; 10.1001/jama.2020.4683. \\ 3. Clarfield AM, Dwolatzky T, Brill S, e.a. Israel ad hoc COVID 19 committee. Guidelines for care of older persons during a pandemic. J Am Geriatr Soc. 2020.}

\section{Samenvatting \\ $\rightarrow$ De wereldwijde reactie op de COVID-19-pandemie met betrekking tot palliatieve zorg voor mensen met dementie weerspiegelt de al langer bestaande uitdagingen van het thema palliatieve zorg in de langdu- rige-zorgsector. Dit artikel formuleert, op basis van 25 artikelen, praktische verpleegkundige adviezen voor pallia- tieve dementiezorg tijdens COVID-19 binnen de langdurige zorg \\ $\rightarrow$ De ongekende COVID-19-situatie wekt een speciale behoefte aan}

4. Brown EE, Kumar S, Rajji TK, e.a. Anticipating and Mitigating the Impact of the COVID-19 Pandemic on Alzheimer's Disease and Related Dementias. Am J Geriatr Psychiatry. 2020.

5. Livingston $G$, Weidner W \&Alzheimer's Disease International. COVID-19 and dementia: Difficult decisions about hospital admission and triage. 2020.

6. van der Steen JT, Radbruch L, Hertogh CM, e.a. White paper defining optimal palliative care in older people with dementia: a Delphi study and recommendations from the European Association for Palliative Care. Palliat Med. 2014;28:197-209.

7. Peters MD, Godfrey CM, McInerney $P$, e.a. The Joanna Briggs Institute Reviewers' Manual 2015. In: Methodology for JBI Scoping Reviews. Adelaide:The Joanna Briggs Institute. 8. Hashimie J, Schultz SK \& Stewart JT. Palliative Care for Dementia: 2020 Update. Clin Geriatr Med. 2020;36:329-339.

9. van der Steen JT. Dying with dementia: what we know after more than a decade of research. J Alzheimers Dis. 2010;22:37-55. 10. Mataqi M \& Aslanpour Z. Factors influencing palliative care in advanced dementia: $a$ systematic review. BMJ Support Palliat. 2019.

1 1.Senderovich H \& Retnasothie S. A systematic review of the integration of palliative care in dementia management. Palliat Support Care. 2019: 1-12.

12. Downar J \& Seccareccia D. Palliating a pandemic: 'All patients must be cared for'. J Pain Symptom Manag. 2010;39:291-295.

13. Brennan F. Palliative Care as an International Human Right. J Pain Symptom Manag. 2007; 33: 494-499.

14.British Geriatrics Society. COVID-19: Managing the COVID-19 pandemic in care homes for older people. 2020.

15. Borasio GD, Gamondi C, Obrist M, e.a. COVID-19: decision making and palliative care. Swiss Med Wkly 2020;150:w20233.

16.Kunz R \& Minder M. COVID-19 pandemic: palliative care for elderly and frail patients at home and in residential and nursing homes. Swiss Med Wkly. 2020; 150:w20235.

17. Wallace CL, Wladkowski SP, Gibson A, e.a. Grief During the COVID-19 Pandemic: Considerations for Palliative Care Providers. J Pain Symptom Manag. 2020.

18.Moore KJ, Sampson EL, Kupeli N, e.a. Supporting families in end-of-life care and bereavement in the COVID-19 Era. Int Psychogeriatr. 2020: 1-10.

19.Otani H, Yoshida S, Morita T, e.a. Meaningful Communication Before Death, but Not Present at the Time of Death Itself, Is Associated With Better Outcomes on Measures of Depression and Complicated Grief Among Bereaved Family Members of Cancer Patients. J Pain Symptom Manag. 2017:54:273-279. 20.Shore JC, Gelber MW, Koch LM, e.a. Anticipatory Grief:An Evidence-Based Approach. J Hosp Palliat Nurs. 2016;18(1);15-19. 
CS bohn stafleu L van loghum

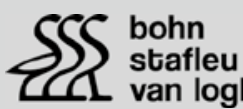
bohn stafleu van loghum

Cohn stafleu

van loghum

bohn stafleu van loghum

CS bohn stafleu L van loghum

Cohn stafleu van loghum

Sohn stafleu

L van loghum
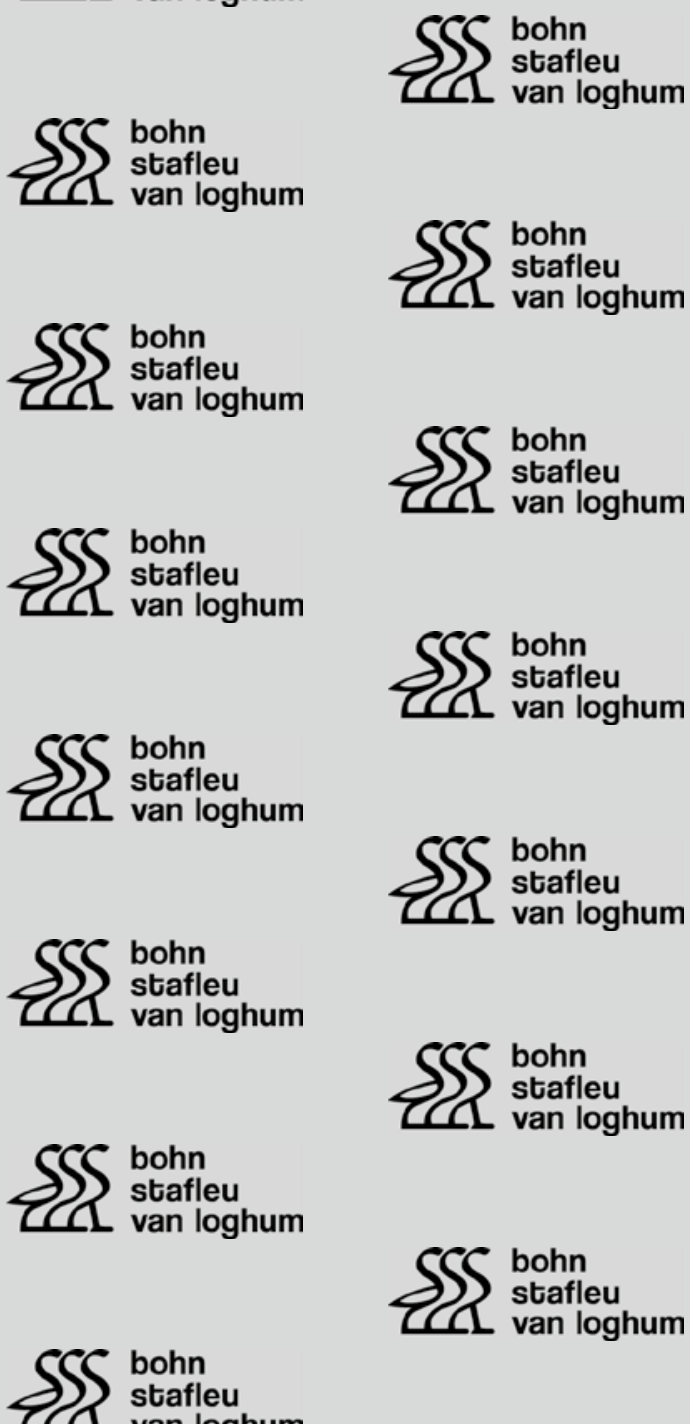

CI van loghum

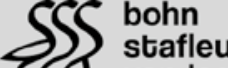

CL van loghum

SSS bohn

CL van loghum

SSS bohn

CL van loghum

CS bohn

stafleu

van loghum
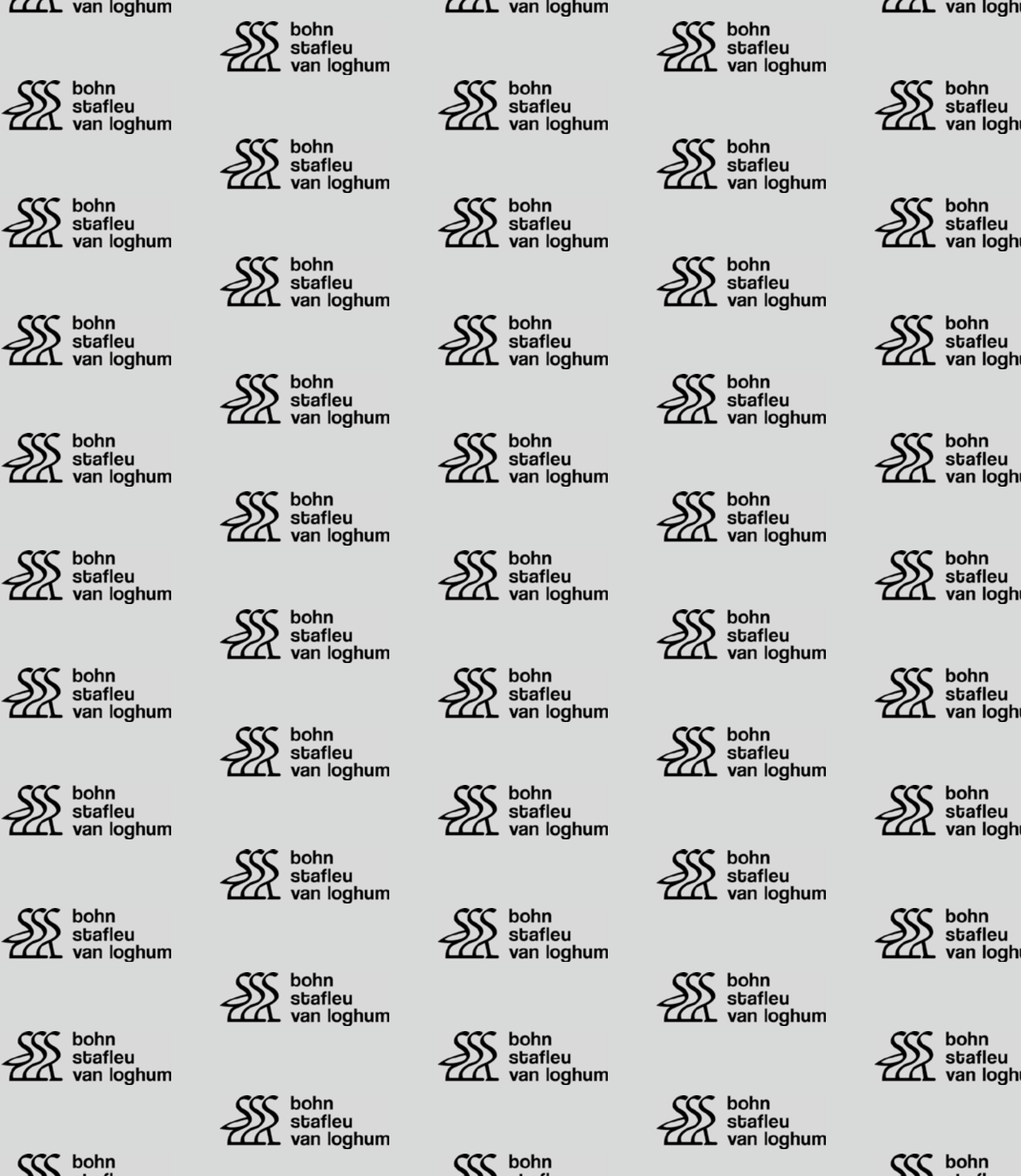

SSS lahn $\begin{aligned} & \text { bohn } \\ & \text { stafleu } \\ & \text { van logh }\end{aligned}$

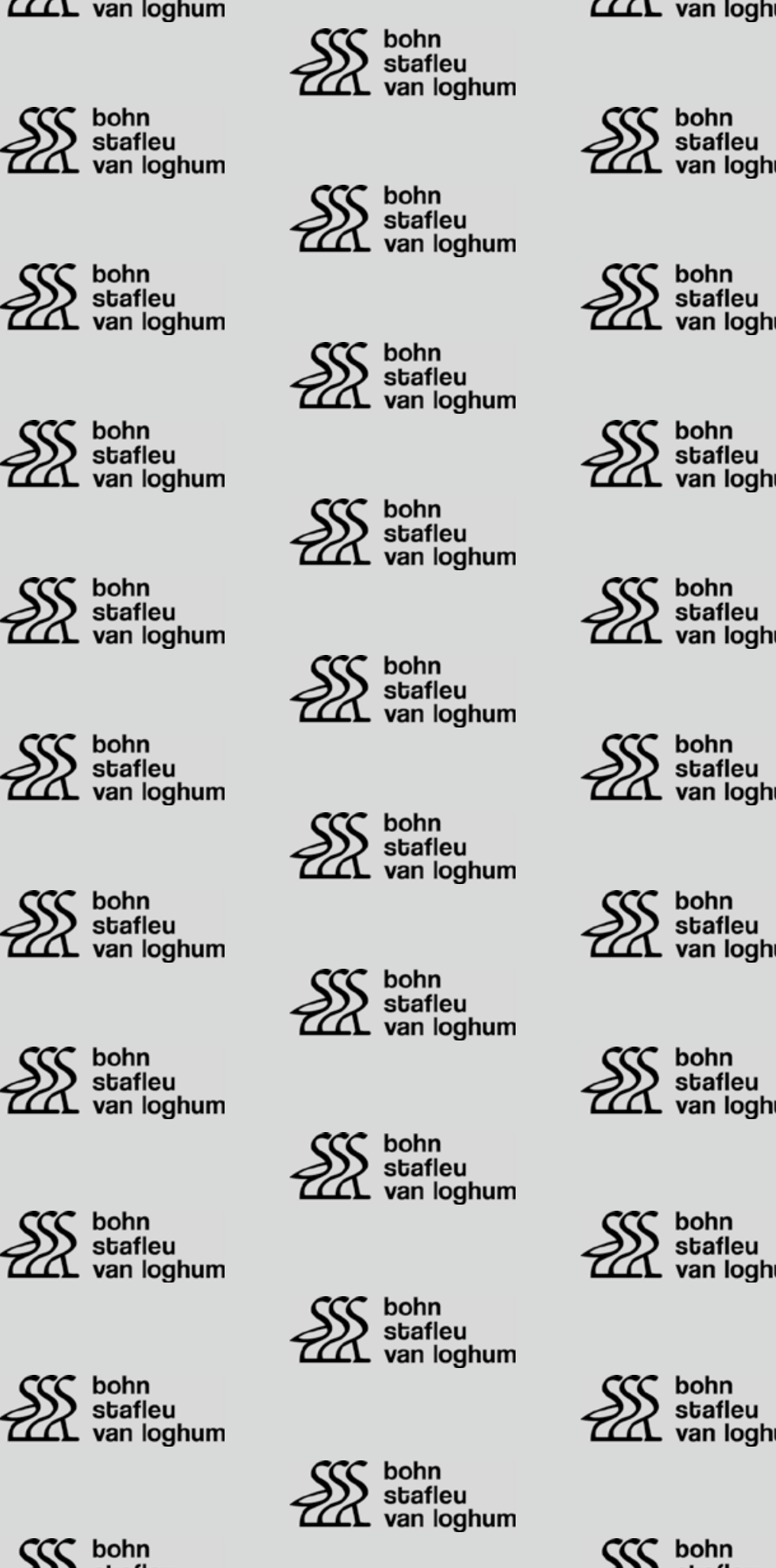

SSS bohn

CIL van loghum

@) stafleu

LL van loghum

SSS bohn

CL van loghum

SSS bohn

CL van loghum
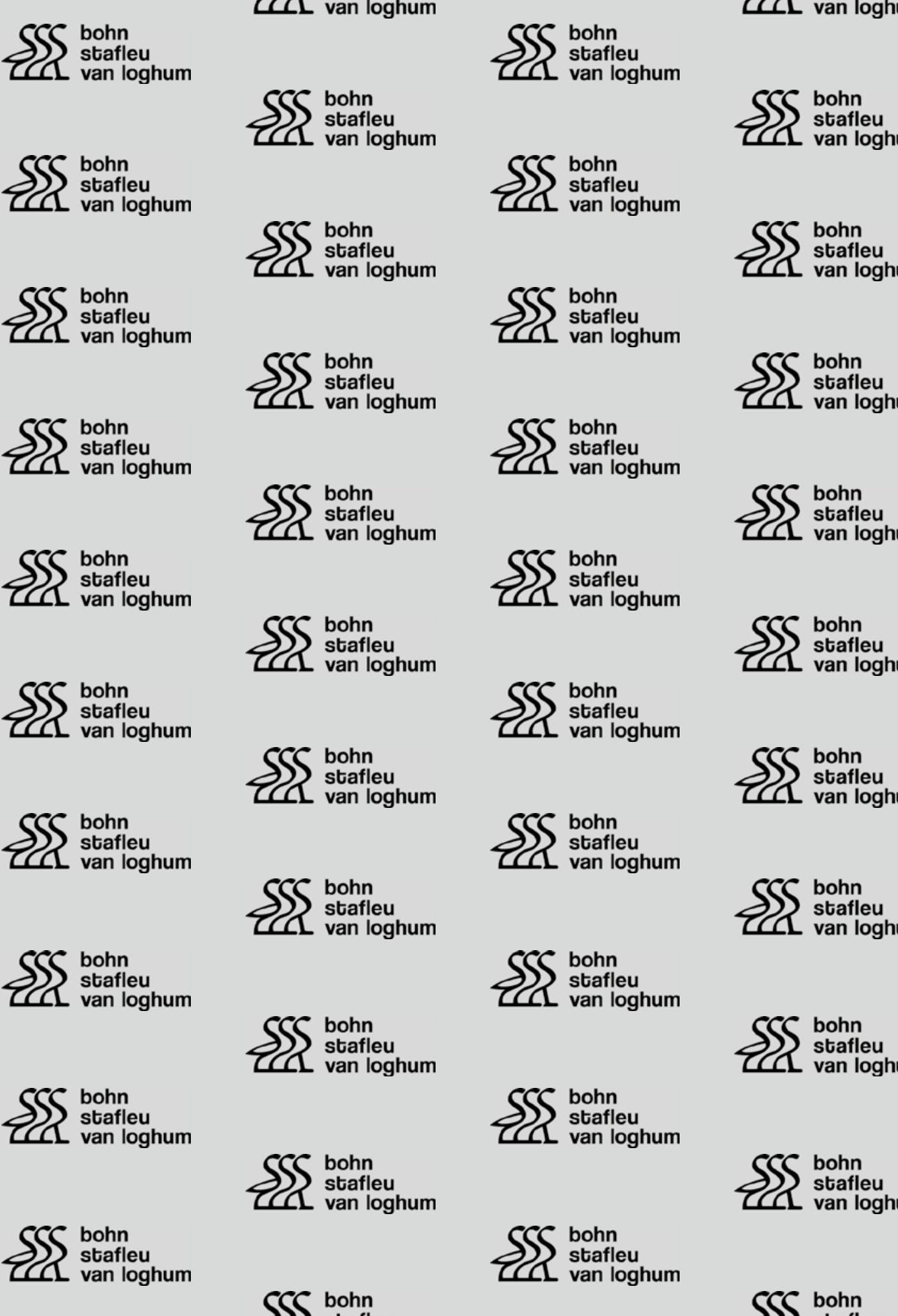

CL van loghum
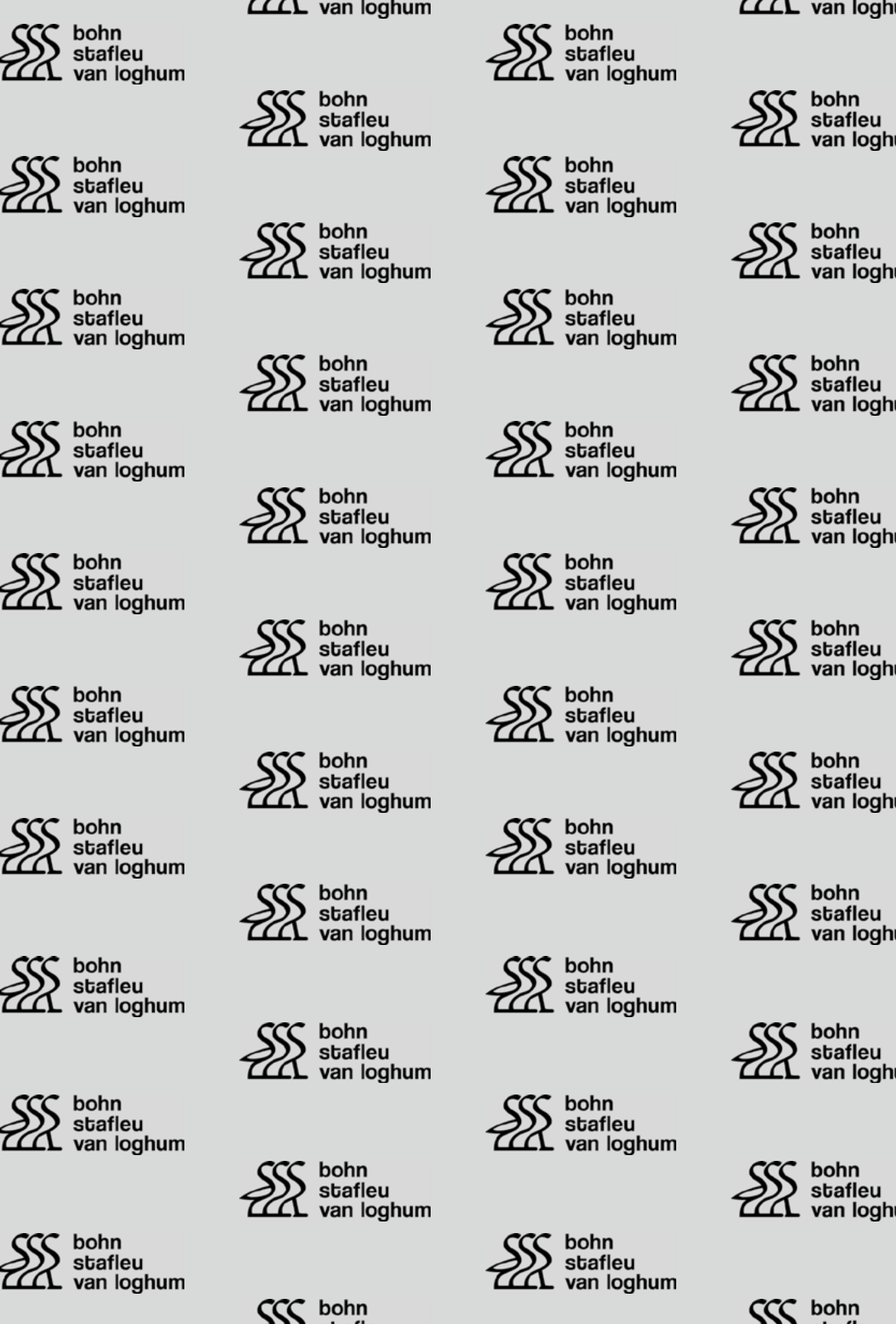

SSS bohn

LI van loghum

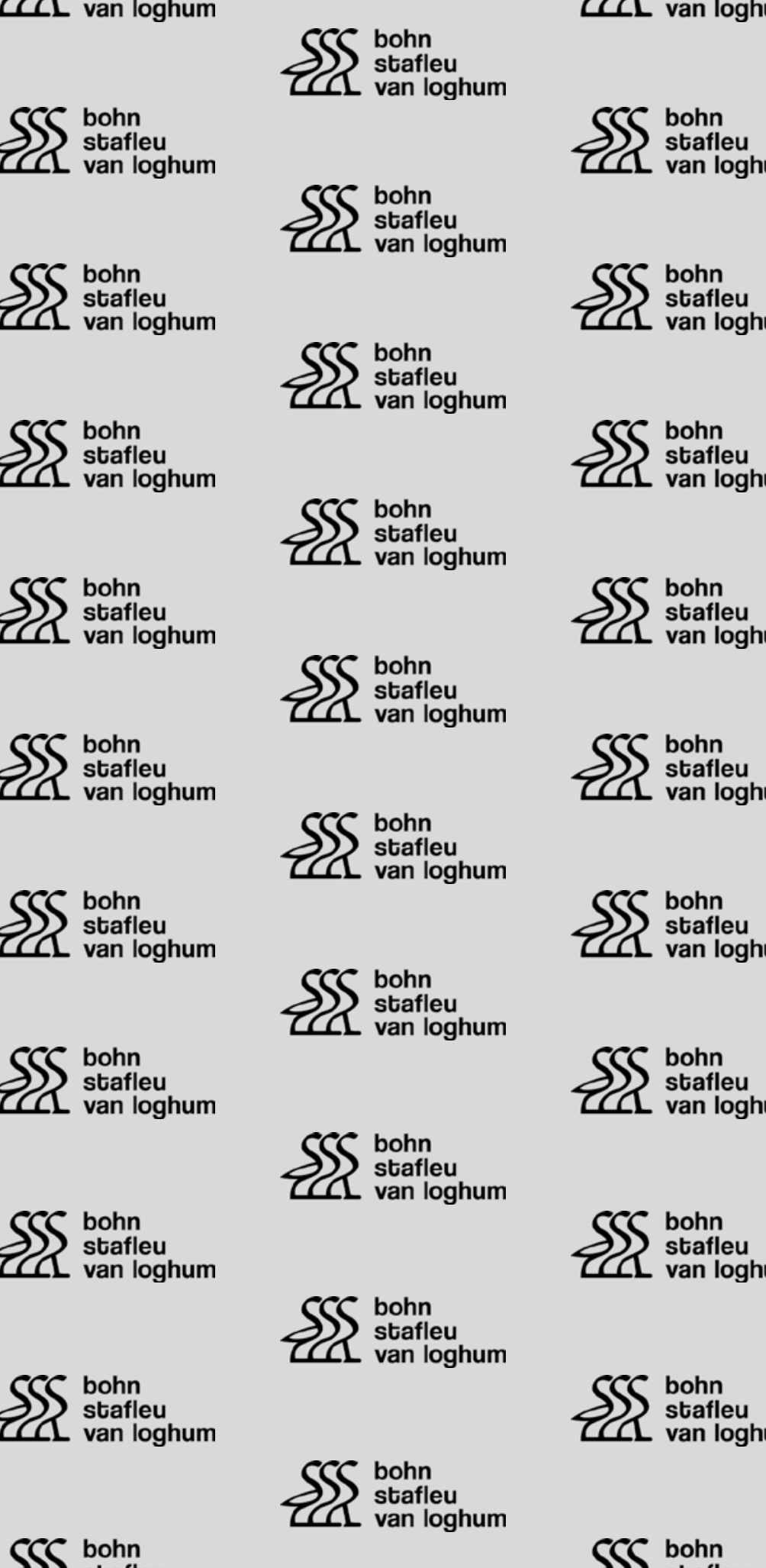

CL van loghum

bohn

stafleu

van loghum

SSS bohn stafleu van loghum

CS bohn stafleu van loghum

SSS bohn

P) stafleu

CL van loghum

Cohn

stafleu

L van loghum

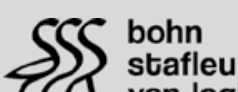

9) stafleu

CL van loghum

CS bohn

stafleu

L van loghum

SSS bohn

CIL van loghum

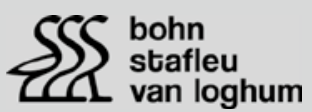

9S bohn

CL van loghum

SSS bohn

CL van loghum

SSS bohn

CL van loghum

SSS bohn

van loghum

SSS bohn

CI van loghum

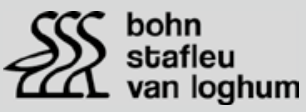

SSS bohn

SSS bohn

Lan loghum

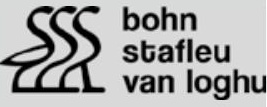

SSS bohn

CL van loghum
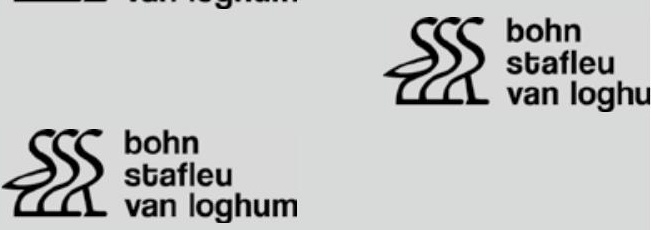

bohn

stafleu

van loghum
CS bohn

P) stafleu LCL van loghum

CL van loghum 